\title{
En términos generales: marco y enunciación
}

\author{
En términos generales: frame and enunciation
}

\author{
Catalina Fuentes Rodríguez - José García Pérez \\ Universidad de Sevilla
}

\begin{abstract}
Resumen. El presente trabajo tiene por objetivo la identificación y delimitación del operador enunciativo en términos generales. Para ello, se ha partido metodológicamente de la Lingüística pragmática, tomando un enfoque macrosintáctico. Diferenciamos, así, su función como complemento circunstancial, dependiente del verbo principal de la oración, de aquellas otras situaciones en las que esta forma se encuentra en la periferia del enunciado, aislado por pausas, bien aún dependiente de un verbo de decir o de intelección presente en la oración (complemento marco), bien ya como un operador discursivo. En este último estadio en términos generales es una unidad fraseológica con un valor procedimental: el hablante indica que transmite su mensaje de manera no detallada ni fiel a la realidad. Advierte del incumplimiento de las máximas de cantidad y calidad, para así evitar posibles objeciones. De este modo, esta construcción entra a formar parte del mismo paradigma que otros elementos que comparten su base léxica y su función enunciativa: en general, por lo general o generalmente. Constatamos, además, la rentabilidad de un adjetivo como general en la formación de operadores del discurso.
\end{abstract}

Palabras clave: operador discursivo, macrosintaxis, enunciación, gramaticalización.

Abstract. This paper aims at identifying and describing the operator en términos generales. In order to do so this structure has been analysed from the perspective of linguistic pragmatics, taking a macrosyntactic approach. Consequently, we distinguish its function as a circumstantial adjunct, dependent on the main verb of the clause, from other cases in which it is located at the periphery

Data de recepción: 01-08-2019 - Data de aceptación: 14-10-2019. 
of the clause, separated by pauses, either still dependent on a verb of saying or thinking present in the clause (frame adjunct), or as a discourse operator. In the latter stage en términos generales is a phraseological unit with a procedural meaning: the speaker indicates that he/she transmits his/ her message in a way that is neither detailed nor faithful to reality. He/she warns the interlocutor that the maxims of quantity and quality are not being complied with, in order to avoid possible objections. In this way, this construction joins the same paradigm as other elements that share its lexical base and its declarative function: en general, por lo general, or generalmente. In addition, we observe the profitability of the adjective general in the development of discourse operators.

Keywords: discourse marker, macro-syntax, statement, grammaticalization.

\section{INTRODUCCIÓN}

El presente trabajo ${ }^{1}$ tiene por objetivo la delimitación del proceso de gramaticalización sufrido por en términos generales en su uso como operador enunciativo de generalización, campo que apenas ha recibido atención en el ámbito de la filología hispánica. Esta función está directamente relacionada con el marco asertivo, generalmente en posición periférica.

El proceso significativo sufrido por esta construcción tiene su raíz en el contenido semántico de sus miembros nucleares: por una parte, por el contenido del adjetivo general, ligado al decir (delimita una restricción a la aserción y un estilo no preciso) $y$, por otra, a través de la oposición 'general' $v s$. 'concreto' como mecanismo de estructuración textual. Desarrolla un contenido procedimental que acaba fijándose y adquiriendo una función macroestructural, concretamente del plano enunciativo, pudiendo tener efectos corteses o desrealizantes.

El objetivo de este artículo es describir los usos de en términos generales, determinar su función en el enunciado y el proceso de gramaticalización desarrollado. Por último, describiremos su categoría como operador discursivo, en línea con los objetivos del proyecto en el que se enmarca este trabajo. El corpus empleado para este estudio se centra en los resultados del corpus CREA. La metodología de análisis es la lingüística pragmática.

Abordamos el estudio del discurso desde la influencia de su contexto de producción, desde el uso. Por tanto, trataremos de responder a la pregunta de cuándo, en qué distribución y con qué objetivo usa el hablante esta expresión.

Este trabajo forma parte del Proyecto I+D-I De Construcciones Periféricas a Operadores Discursivos: un Estudio Macrosintáctico del Español Actual (FFI2017-82898-P), cofinanciado por el Ministerio de Economía y Competitividad y fondos FEDER. 
Nuestro enfoque es macrosintáctico. Consideramos, con Blanche-Benveniste (2002, 2003) y como se expuso en Fuentes Rodríguez (2017a) y anteriormente en Fuentes Rodríguez (2007), que el enunciado incluye en su estructura una zona nuclear y otras periféricas. Gutiérrez Ordóñez (1997: 70) diferencia argumentos, aditamentos y circunstantes. Estos últimos son elementos externos al conjunto oracional formado por el verbo y expresan contenidos relacionados con la propia enunciación ${ }^{2}$ :

- Circunstantes de referencia: Hablando de esta noticia, nada tengo que comentar; En lo que se refiere a la salud, todos estamos bien.

- La determinación del marco o la perspectiva desde la que se emite el enunciado, los llamados tópicos: Lingüísticamente, ¿esto es correcto?

- Circunstantes de causalidad: pueden ser causales (Porque es listo, resolvió el problema), condicionales (Si la fiebre sube, avisa al médico) y concesivos (Aunque le guste el fútbol, no vendrá).

— Circunstantes espaciales y temporales: En León, estudia; En este convento, murió la santa.

Fuentes Rodríguez (2005) parte de esta clasificación y la completa estableciendo diferentes niveles periféricos. El complemento marco o circunstante expresa una circunstancia (modo, tiempo, causa...) que afecta a toda la oración. Supone un primer nivel de extraproposicionalidad. Afecta directamente al contenido expresado por el verbo, al contenido designativo. Pero hay otros niveles periféricos (Dik 1997; Fuentes Rodríguez 2007): además de la enunciación, que es donde se queda Gutiérrez Ordóñez (complementos o tópicos de la enunciación), también cabe considerar los planos modal, argumentativo e informativo. En el modelo de Fuentes Rodríguez (2017b [2000]) se propone un enfoque modular, poliédrico, que une la microestructura a la macroestructura. Esta última tiene como objetivo describir la organización del discurso en relación con el entorno comunicativo que lo rodea: situación, participantes (hablante-oyente), etc. Con ello la macrosintaxis puede ser entendida como disciplina que analice la estructura del enunciado atendiendo a esos contenidos macroestructurales que están fuera del contenido estrictamente proposicional ${ }^{3}$ y se expresan con complementos periféricos u operadores discursivos (Fuentes Rodríguez 2012, 2015).

2 Sobre la enunciación puede consultarse Benveniste (1970), Récanati (1979), Ducrot (1984), Gaulmyn (1987) y Calsamiglia \& Tusón (1999), entre otros.

3 También en este nivel macroestructural estarían los conectores, llamados por otros autores enlaces extraoracionales, que dan cuenta de las relaciones que cada enunciado, como elemento independiente y autónomo, establece con los demás en la secuencia textual. 
Entre ellos se incluye la referencia a la enunciación, cómo matiza el hablante su decir o indica al oyente cómo debe entenderlo.

En términos generales establece unas indicaciones de cómo ha concebido el hablante su discurso y qué instrucciones proporciona al oyente para su interpretación. Es un elemento, como vamos a ver, propiamente enunciativo.

\section{CONCEPTOS METODOLÓGICOS PREVIOS}

El objetivo del trabajo es determinar los usos de esta estructura y, a la vez, comprobar si es un operador fijado ya o aún no ha completado su proceso de gramaticalización, si es una construcción o un sintagma libre. Para ello es necesario aclarar qué entendemos por operador discursivo.

Fuentes Rodríguez (2019) lo propone como una categoría de la macrosintaxis ya que permite caracterizar comportamientos de paradigmas cerrados de elementos. Los operadores constituyen una clase funcional, un paradigma de unidades delimitadas claramente por su función en el enunciado, por su contenido procedimental y su distribución.

Proceden de palabras (adverbios, sustantivos, verbos o adjetivos) y sintagmas que desarrollan un contenido procedimental sobre distintos aspectos:

- Sobre las circunstancias del decir (los operadores enunciativos como sinceramente, francamente, la verdad)

- Sobre la modalidad (los modales, como afortunadamente, desgraciadamente, menos mal, gracias a Dios)

- Sobre la orientación y fuerza argumentativas (operadores argumentativos como como mucho, al menos, solo)

- Sobre la estructuración de la información (operadores informativos como precisamente)

Pueden aparecer aislados, ocupando el margen izquierdo, el derecho o en posición intermedia (parentético), o bien pueden emplearse integrados en la oración. Su alcance puede ser todo lo dicho en el enunciado o solo un segmento, pero en ningún caso desempeñan función alguna respecto al verbo.

Estos contenidos macroestructurales pueden ser expresados también por estructuras libres, los complementos periféricos. Por ello nuestra tarea aquí será demostrar cómo la construcción en términos generales ha ido fijándose, pasando de tener un contenido referencial como complemento circunstancial de modo o manera a tener un contenido procedimental como operador de generalización, usado por el hablante para señalar que aquello que enuncia no se hace con detalle, sino de manera genérica, 
superficial, etc. Tenemos que demostrar con el análisis su grado de fijación y decidir si la generalización es un contenido enunciativo, del decir, de la aserción, o una función cercana al circunstante, un concepto ligado al ámbito de realización de un hecho.

En español encontramos operadores relacionados con la generalización de la misma base léxica: por lo general, en general, generalmente, pero ¿son equivalentes? ¿Cómo se dividen el espacio procedimental? Y además, ¿la generalización entra dentro de las expresiones indirectas, va contra la máxima de cantidad o calidad? En el fondo, este recurso ¿qué justificación discursiva tiene? ¿Cuál es su contexto pragmático de empleo? Todas estas preguntas se derivan de un enfoque pragmático ${ }^{4}$ y vamos a intentar responderlas tomando como base los corpus CREA y CORPES XXI.

\section{PRESENCIA DE EN TÉRMINOS GENERALES EN LA BIBLIOGRAFÍA}

En términos generales no aparece recogido en ninguno de los repertorios lexicográficos dedicados a la recopilación de este tipo de unidades. No lo incluye el Diccionario de partículas discursivas del español (2008-hoy) del grupo Val.Es.Co. ni tampoco el Diccionario de conectores y operadores del español de Catalina Fuentes Rodríguez (2018a [2009]). Tan solo Luis Santos Río, en su Diccionario de partículas (2003) recoge, por un lado, en líneas generales (2003: 398):

\section{EN LÍNEAS GENERALES}

Loc. adv. c. (cercanía semántica amplificadora)

Se emplea para indicar que lo que se dice tiene la limitación de producirse sólo a grandes rasgos y no en detalle. En líneas generales, el texto de la traducción respeta el original. Coincide, en líneas generales, con lo que ya dijo en el discurso de otoño.

Por otro lado, en términos generales se encuentra en las entradas derivadas de en términos..., donde el autor diferencia varias posibilidades, en este orden (Santos Río 2003: 626-627):

1. en términos + adjetivo calificativo

Cir. orac. m. realizativo ustedes pasarían a la situación prevista en el decreto de regulación laboral. En términos más explícitos y coloquiales, se irían todos ustedes a tomar por el culo.

$4 \quad$ En el modelo de Lingüística Pragmática se tiene en cuenta la superestructura o tipo discursivo, así como las diferentes macroestructuras: la intervención del hablante en modalidad y enunciación o la orientación al receptor a través de la organización informativa y argumentativa. En todos los casos los elementos de base son los de la microestructura. 
2. en términos + adjetivo relacional aspectivo

Circ. respectual aspectivo

En términos económicos el desastre ha sido muy grave.

3. en términos + adjetivo relacional «perspectival»

Cir. orac. m. realizativo

una actuación no válida. En términos jurídicos, «nula de pleno derecho».

4. en términos + de $\mathrm{SN}$

Circ. orac. m. realizativo

repoblarla con roble americano (en términos de la Botánica, quercus rubra).

5. en términos generales

Loc. adv. orac. cuantitativa (Cerca semántica amplificadora)

En términos generales, el comportamiento del profesorado es bueno.

6. en términos relativos

Circ. orac. respectual

En términos relativos, esto ha sido una victoria.

En primer lugar, sorprende que, siendo general un adjetivo calificativo, no esté incluido en términos generales en el primer apartado, lo que demuestra que el autor ha tenido en cuenta su amplia recurrencia y su autonomía dentro del sistema, reconociéndole una función diferente de otras combinaciones. Veamos la definición completa:

\section{EN TÉRMINOS GENERALES}

Loc. adv. orac. cuantitativa (Cerca semántica amplificadora)

En general, globalmente. Es periférica. Se pronuncia con entonación ascendente (salvo cuando figura como coletilla) y va seguida de pausa marcada. En términos generales, el comportamiento del profesorado es bueno. El comportamiento del profesorado es, en términos generales, bueno. El comportamiento del profesorado es bueno, en términos generales. -¿Es bueno el comportamiento del profesorado? -En términos generales, sí.

Como se ve, Santos Río califica en términos generales como una locución adverbial oracional, señalando así que su ámbito de actuación es toda la oración, todo el contenido proposicional, y no un segmento. El mismo hecho de considerarla adverbial implica su dependencia del núcleo verbal de la oración a la que afecta. Sin embargo, en el siguiente ejemplo observamos dos oraciones coordinadas y en términos generales recae sobre ambas, por lo que su función es la de circunstante marco de todo el enunciado:

1. Intentamos demostrar cómo el sistema sexo-género con dominante masculino contribuye a perpetuar la concepción de que la política es una actividad reconocida y legítima del gobierno, de los parlamentos o legislaturas, de los partidos políticos. Cómo, en términos 
generales, el Estado le atribuye al sistema sexo-género con dominante masculino la exclusividad y el universo posible de participación política, a la vez que niega la multiplicidad de aspectos de la política que lo rebasan. Específicamente, niega, disimula u oculta la política sexual en el ámbito privado y público [CREA, 1989, Puerto Rico].

Nótese, además, el hecho de la oposición semántica 'general' vs. 'específico', que sirve para estructurar el párrafo y establecer la relación entre los dos enunciados. En términos generales cuenta con pocos estudios, por lo que es necesario abordar sus análisis desde los textos.

\section{EN TÉRMINOS GENERALES, ¿OPERADOR DISCURSIVO?}

Siguiendo la línea de otros trabajos inscritos en nuestro proyecto de investigación, describiremos el funcionamiento de esta expresión en todos sus contextos de aparición para responder a la pregunta básica de investigación: ¿es un operador discursivo fijado? Para ello debe cumplir las condiciones que establecemos en el apartado 4.2.4. Estos rasgos delimitan un proceso que en otros casos analizados previamente pasa por los siguientes estadios: complemento verbal $\rightarrow$ periférico $\rightarrow$ operador discursivo, aunque se permite la coexistencia (Hopper 1991; Brinton 1996; Jucker \& Ziv 1998; Hopper \& Traugott 2003; Traugott 1995; Lehman 2002; Company 2004a y b) y la gradualidad (Traugott \& Trousdale 2013). Entre el punto de partida y de llegada hay todo un continuum que debe ser descrito y que puede aportar mucha información para entender la sintaxis discursiva.

\subsection{Complemento verbal}

Como en otras ocasiones, la primera función en microsintaxis (marco oracional) es la de un complemento verbal, ya sea circunstancial o argumental. En este caso son varias las opciones:

3.1.1 En términos generales es una construcción de base nominal. Al estar introducida por una preposición, se entiende con función modificadora, generalmente como complemento de modo o manera, dependiente del verbo, indicando que algo se hace de forma no exhaustiva o no concreta. La RAE/ASALE (2014) define el adjetivo general así: 
general

Del lat. generālis.

1. adj. Común a todos los individuos que constituyen un todo, o a muchos objetos, aunque sean de naturaleza diferente.

2. adj. Común, frecuente, usual.

Pero no recoge la construcción que estudiamos ni bajo general ni bajo término, sustantivo que hace referencia al decir, lo que condiciona su función. De hecho, se encuentra en contextos circunstanciales en los que el adjetivo general se combina con otros:

2. Francisco Umbral, quien escribe columnas en la prensa española desde hace 30 años, tercia en este transitorio debate: «Se supone que la línea del articulista es coherente con la del diario en términos generales y amplios, aunque no está mal $-\mathrm{y}$ se produce en algunas publicaciones - que existan disidencias, siempre que no sean escandalosas [...]» [CREA, 1995, España].

3. En efecto, como habrá podido esperarse, si bien la primera hipótesis que define la supuesta eventualidad que define al estado de anarquía se encuentra impecablemente formulada, y con ello no quiere decirse más del hecho de que Locke la establece en términos generales y abstractos; la segunda hipótesis contiene dos fracasos del propósito de abstracción ideológico que guía la escritura lockiana [CREA, 1986, México].

4. Con todo lo dicho, nada se ha dicho todavía acerca del tema de la violencia en la sociedad contemporánea, considerado en términos generales y básicos [CREA, 1980, España].

En estos casos se usa una construcción libre. Cada elemento tiene su contenido léxico asignado y su función es la de modificador de modo: «es coherente en términos generales», «la establece de un modo concreto: en términos generales». En los casos siguientes aparece como modificador de un sintagma, aunque este incluye un sustantivo o adjetivo deverbal, por lo que sigue modificando a un hecho o proceso:

5. Al incursionar sobre aspectos globales del proceso económico, Aguado, tras expresar que «debemos ser conscientes de que lo que está fallando aquí es una reactivación de la economía en términos generales», recordó que la entidad siempre había adherido a los principios de la libertad de comercio [...] [CREA, 1979, Argentina].

6. Lo importante en el film, como tal, es la manera en que la guerra civil es utilizada como pretexto para construir una metáfora definitoria de la Historia de España en términos generales, [...] [CREA, 2000, España].

En el ejemplo 7, indica el ámbito en que se produce un elemento, como complemento del verbo es: 
7. Las autoridades de la isla explicaron que el apoyo entregado por la Asamblea fue en términos generales y que tampoco estuvo referido al tema de Bolivia en particular [CREA, 2004, Chile].

3.1.2 Detectamos un contexto especial de complemento verbal cuando se combina con un verbo de habla y también de intelección, que normalmente hace referencia a la persona del locutor o de los enunciadores que se activan, indicando la forma en la que se quiere que los receptores entiendan la enunciación en el caso de los verbos de lengua y exponiendo el modo en que concibe, juzga o asume la entidad en cuestión en el caso de los verbos de pensamiento. Pero creemos que hay que establecer una diferencia para poder entender el proceso.

Con un verbo de habla puede indicar el modo en que se «expresa» algo. El sustantivo término lo indica claramente por su significado. Encontramos hablar, llamar, calificarse, describir, indicar, formular como núcleos modificados por en términos generales:

8. Las tres noches de música africana en Madrid significaron un saludable ejercicio mental, pues no está mal acercarse de cuando en cuando a lógicas musicales tan antiguas como desconocidas. El intento no es fácil, porque es imposible hablar de música africana en términos generales [CREA, 1986, España].

9. Los ministros de Asuntos Exteriores han levantado recientemente acta de los problemas domésticos de cada Estado miembro. Hay amplias diferencias de lo que llamaríamos en términos generales riqueza y pobreza, que se traducen en distintos niveles tecnológicos [CREA, 1984, España].

10. Hoy volveremos a tener sol en abundancia, aunque asimismo algo de viento, sobre todo en el valle del Ebro, y temperaturas que podrá calificarse como suaves en términos generales [CREA, 1982, España].

11. El premio Nobel de Economía Amartya Sen propuso que, en lugar de hablar en términos generales de satisfacción de necesidades, la economía debería centrarse en la idea de cómo dotar a todos los seres humanos de capacidades, entendiendo por capacidad todo aquello que permite a los seres humanos que sus derechos formales como personas se conviertan en libertades reales, efectivas [CORPES XXI, 2016, España].

12. En el análisis anterior se describe en términos generales algunas de las condiciones en las que la mujer se inserta en el mercado laboral; [...] [CREA, 1993, Guatemala].

13. En síntesis, estos datos dan cuenta en términos generales de una desvinculación respecto de espacios tradicionales de socialización que resultan claves para la infancia y la adolescencia, tanto en lo que hace al ejercicio de sus derechos como en términos de protección y desarrollo integral [CORPES XXI, 2016, Uruguay].

14. Por otro lado, diremos, en las figuras mismas, hay una integración de figuras, llamémoslo así, en términos generales, de figuras entre las entre las cultura quechua, aymara y hasta te podría decir, a maya y azteca [...] [CREA, Bolivia, Oral]. 
15. No obstante, podemos indicar en términos generales los siguientes objetivos publicitarios: [...] [CREA, 1991, España].

16. A la hora de abordar estos temas, hay que subrayar la dificultad que entraña referirse en términos generales a dos espacios tan heterogéneos [CREA, 2002, España].

En estos casos, aunque generales modifica a términos con contenido relativo al decir, no aparece la construcción como complemento periférico, sino que sigue actuando como complemento del verbo, aunque este es de habla. Es frecuente encontrarlo intercalado entre verbo y complemento directo, como en (9), (12) y (15). El valor de generalización actúa como marco de esa acción. En el ejemplo (17) se pospone:

17. Así, por ejemplo, los convenants americanos, el sistema de legalidad que se encarna en las actuales Leyes Fundamentales españolas o la Constitución soviética de 1918, responden a normas supuestas diferenciadas: crean tres sistemas de legalidad distintos. Es evidente que aquí exponemos nuestra tesis en términos generales: existen legalidades no-tipificables en los modelos citados [CREA, 1982, España].

Lo encontramos al inicio de una oración, con una función más englobadora:

18. Martín-Lobo (2003), describe cómo la experiencia indica que, en términos generales, las actividades sensoriales facilitan la comprensión [CORPES XXI, 2016, España].

Es frecuente su aparición con hablar o decir, en aclaraciones. Puede ser una oración que actúa sobre otra en el enunciado (19) o un enunciado que aclara el anterior (20):

19. No, si no lo digo por estos señores, que los acabamos de conocer y son amigos de aquí, de Conejo, y con eso me basta; lo digo en términos generales [CREA, 1985, España].

20. MARCELO

El tiempo es cruel nada más para las personas que no aceptan que pasa el tiempo.

RENATA

¿Lo dices por mí?

MARCELO

Es una idea abstracta. hablo en términos generales [CREA, 1975, México].

En todos estos casos lo consideraríamos un complemento circunstancial de modo de un verbo de habla explícito. En otros casos modifica a un verbo nocional: considerar, conocer, significar o, entre otros, creer:

21. Los resultados obtenidos en las pruebas aplicadas pueden considerarse en términos generales moderadamente satisfactorios [...] [CREA, 1999, España]. 
22. La adopción masiva de los productos con látex ha dado lugar al surgimiento de una nueva patología, aún hoy no totalmente comprendida, conocida en términos generales como alergia al látex [CORPES XXI, 2016, Argentina].

23. En lo que hace referencia al sonido en términos generales, su clasificación suele atender a su localización y origen en función de la imagen [...] [CREA, 2000, España].

24. Crítica que se basaba en sus defectos pero que muchas veces se lanzó en términos generales y de manera fiera contra la institución del partido político [CREA, 2002, Venezuela].

25. Yo creo en términos generales los mexicanos debemos creer más en nosotros y a lo mejor también los medios de información debieran tomar una actitud más comprensiva [CREA, 2000, México].

26. Hoy no solamente estamos deliberando en términos generales, estamos haciendo propuestas absolutamente serias, técnicamente elaboradas con todo el rigor, [...] [CREA, 1998, México].

3.1.3 Un segundo contexto en que esta expresión actúa con valor léxico es la correlación con en particular, estableciendo una relación cohesiva. La rentabilidad de esta construcción reside en la oposición semántica que se establece entre los adjetivos 'general' frente a 'concreto', 'particular', etc., de tal manera que muchos hablantes la utilizan como una forma de estructuración textual, con toda clase de verbos. El semantismo establece una estructura paralelística basada en el diferente ámbito de las aserciones. El sintagma sigue funcionando como complemento verbal:

27. De ahí que el pronunciamiento de la Corte no sólo se refiere al caso en particular sino que se proyecta en términos generales a definir el alcance de la tutela en materia de orden público [CREA, 1996, Colombia].

En el siguiente se opone «aspectos económicos» a «términos generales» y en (29) «detalle» a «términos generales». El grado de concreción del primero contrasta con la fijación que ya vemos en el propio significado del segundo:

28. Las organizaciones magisteriales presentaron a consideración de las autoridades educativas un pliego de peticiones que no solo abarcan aspectos económicos, sino que mejoren las condiciones de la educación en términos generales [CREA, 1997, Panamá].

29. De lo que no se pudo hablar con mucho detalle, sino en términos generales, fue del muy esperado canje de bonos, el mismo que ayer elevó la algarabía en los corazones de Wall Street [CREA, 2001, Argentina].

Esta estructura opositiva funciona también cuando estas expresiones actúan como complementos periféricos, de complemento marco: 
30. $-¿ Y$ usted hacia dónde va?

-En términos concretos no tiene importancia, en términos generales le diré que, siempre, hacia la izquierda [CREA, 1990, España].

\subsection{Complementos periféricos}

La pausa actúa como marcador de esta incidencia general, proposicional. Lo hace grupo entonativo independiente, uno de los rasgos característicos de los marcadores discursivos (Fuentes Rodríguez 1996, 2018a [2009]; Quirk et alii 1972; Brinton 2010). Entre las funciones periféricas que desempeñan encontramos varios complementos.

\subsubsection{Complemento marco}

La función más cercana a su contenido léxico y a su función como complemento verbal es la de complemento marco, un paso a la periferia que hace que afecte a todo el enunciado. Expresa el ámbito general en que se desarrolla la acción verbal (generalmente verbos de consideración o conocimiento) o el ámbito del decir, de la aserción. Sería un circunstante o tópico (Gutiérrez Ordóñez 1997). El siguiente ejemplo presenta dos usos. El primero, al inicio, establece el marco de la aserción y el segundo modifica al verbo hablar.

31. Pero esta esta este grupo, esta sociedad Exalumnos que está forma parte de la universidad, ¿que qué propósito tiene?, porque yo soy exalumna y jamás se me ha ocurrido pertenecer a ella. Sí, bueno, o sea, yo no podría En términos generales, estamos siempre hablando en términos generales. Sí, yo no podría entrar en detalles porque obviamente desconozco los detalles, naturalmente, las minucias, no trabajo con ello [CREA, Puerto Rico, Oral].

En posición final, en el margen derecho, obliga a reconsiderar todo lo dicho anteriormente, función propia de esta zona del enunciado (Fuentes Rodríguez 2012):

32. Pero a partir del año pasado, en la séptima edición, el criterio cambió para dar entrada a las exposiciones que sus mentores (en ésta de 1988, Ángel González y José Miguel Ullán) consideran como de mayor interés, así, en términos generales [CREA, 1988, España].

\subsubsection{Complemento periférico de enunciación}

La segunda función se refiere al acto de decir (Benveniste 1977). En términos generales ya no es un sintagma que modifica al verbo de la oración. Su punto de anclaje es el 
verbo performativo sobreentendido en toda comunicación (Austin 1965; Ross 1970): «Yo afirmo en términos generales que...». En esta función suele aparecer en posición inicial entre pausas. Así establece una función con alcance general, en el margen izquierdo, pero también lo encontramos intercalado o al final, entre pausas. Estas sirven para marcar la extraproposicionalidad, como en cualquier operador discursivo. El número de ejemplos es elevado. Generalmente se combina con verbos de habla, como ya vimos en su empleo como modificador verbal. Esto nos plantea problemas de delimitación. La pausa - gráfica - sirve para marcar la extraproposicionalidad y el deseo de establecer una referencia al decir que afecta a todo el enunciado y apunta al hablante.

33. No es sencillo determinar las razones de ello, pero sí podría aventurarse que, en términos generales, el bien común se considera un concepto excesivamente general y abstracto en una época en la que la política y el derecho han perdido su dimensión ideológica [CORPES XXI, 2013, Colombia].

Lo anterior podría reformularse como: «hablando en términos generales». La construcción funciona como complemento periférico de enunciación, también con verbos nocionales:

34. El 2005 será el segundo año consecutivo de crecimiento económico lo que significa, en términos generales, un requerimiento adicional de personal por parte de los sectores productivos [CREA, 2004, Venezuela].

Muy frecuentemente en términos generales aparece referido al complemento directo del verbo de habla, que constituye su alcance. En el fragmento siguiente la estructura es: verbo habla + que + en términos generales + oración. La expresión aparece como periférico afectando a esta segunda parte del contenido oracional:

35. Puede decirse que, en términos generales, la meta de la mayoría de estos paleontólogos, fue llegar a establecer una lista de fósiles [...] [CREA, 1987, España].

36. Considero importante hacer notar que, en términos generales, los avances logrados por el hombre siempre le han reportado un beneficio [CREA, 1988, México].

37. Destacó que, en términos generales, el número de personas inculpadas y condenadas por delitos políticos es menos que en años anteriores [CREA, 1997, EE. UU.].

38. Hay que anotar que, en términos generales, la programación ofrecida distaba mucho de ser la convencional y que, por tanto, la iniciación no resultaba fácil [...] [CREA, 1990, México]. 
En estos casos la extraproposicionalidad se marca por su presencia entre pausas para indicar el ámbito en que se debe entender lo que sigue, no una forma de hablar. Generalmente se indica que la aserción es poco matizada:

39. De poco concreto, pero en términos generales, aceptable, calificaron los precandidatos conservadores o de origen conservador el programa de partido presentado el martes por la dirección nacional de la colectividad [CREA, 1997, Colombia].

Aceptable en (39) no tiene todo su contenido semántico, ni toda su extensión en la aplicación, sino solo en el sentido en el que se considera habitualmente. Este complemento enunciativo establece una indicación sobre las características de la aserción que apuntan a la intención del hablante y el contexto de realización. El hablante resta fuerza a su aserción, que se presenta como general y no concreta. Es el desarrollo del contenido macroestructural, procedimental. Es una limitación que parece no respetar la máxima de calidad ni de cantidad. No se proporciona toda la información, no se precisa, sino que se la ofrece de manera genérica. El hablante se implica menos y en caso de valoraciones estas pierden fuerza, tanto las negativas como las positivas. Así, en el siguiente caso el hablante no afirma que no aparece el «autoodio» lingüístico, sino que «hablando de forma genérica» no se percibe, que es lo habitual. Igual en (41) con respecto a la satisfacción. En una escala, «satisfactoria» está en la zona positiva, en términos generales rebaja su valor:

40. Dentro de estos niveles, el autoodio es una forma extrema de respuesta a las lealtades en conflicto. Con ello quiero decir que, en términos generales, el autoodio lingüístico no aparece [...] [CREA, 1977, España].

41. A pesar de la reticencia de Adela de Otero a la hora de revelar detalles sobre sí misma, la relación que mantenía con el profesor de esgrima podía considerarse, en términos generales, satisfactoria para éste [CREA, 1988, España].

Igual ocurre con «satisfecha» en el siguiente, en el que no están indicadas las pausas:

42. A pesar de las críticas de líderes de unos diez partidos, incluido el Frente Sandinista de Liberación Nacional, Zelaya declaró que en términos generales se sentía «satisfecha» con el comportamiento de los funcionarios del CSE en todo el país [CREA, 1996, Costa Rica].

\subsection{4 ¿Operador discursivo?}

Ante la situación descrita nos preguntamos si en estos casos en que aparece entre pausas, antepuesta generalmente, referido al decir, es una construcción libre, periférica 
o un operador discursivo ya, como marca de enunciación. Para afirmar este proceso tienen que darse ciertas condiciones (vid. Hopper 1991; Hopper \& Traugott 2003; Traugott 1995; Company 2004a y b; Fuentes Rodríguez 2014, 2016 a y b, 2018b):

a) Que la construcción adopte un valor único, que actúe como una unidad, sin posibilidad de insertar otros elementos.

b) Que aparezca como grupo entonativo independiente.

c) Que desarrolle un contenido procedimental, relativo al tipo de estilo asertivo: una comunicación no precisa en detalles, sino una afirmación genérica. El hablante elige este estilo comunicativo.

d) Que no tenga función con respecto al verbo de la oración.

Este proceso, como señalan Traugott \& Trousdale (2013), es gradual. Al mismo tiempo las etapas pueden coexistir dando paso a una polifuncionalidad. La construcción que analizamos, en términos generales, cumple la condición b), aparece entre pausas y tiene movilidad, como acabamos de decir, no permite inserción de elementos en medio («en términos muy generales») y muestra su función periférica. Su valor procedimental es enunciativo, aunque con cierto valor marco: «hablando de manera general, sin precisar ni detenerse en detalles». La instrucción al receptor es «entiende esto en general, no de manera concreta». Correspondería a una operación discursiva de generalización, opuesta a la ejemplificación o concreción:

43. En nuestro país, en términos generales, la calidad y el costo de los medios de acceso, fundamentalmente la banda ancha, sigue siendo para una minoría: solo el $9 \%$ de la población tiene una conexión de banda ancha debido al elevado costo de más de 26 dólares mensuales en promedio [CORPES XXI, 2013, México].

44. En términos generales, los seguros que más contratan las personas son vida e invalidez, salud, de automóvil y del hogar [CORPES XXI, 2014, México].

Afecta al enunciado, aunque a veces su alcance es un segmento del enunciado, el complemento directo, otra oración, un sintagma. En el ejemplo (45) encontramos una situación verdaderamente intermedia, porque tenemos el verbo de lengua, es decir, la marca performativa de la enunciación, pero coordinado con un conector. También lo documentamos en otros casos en Fuentes Rodríguez (2018b):

45. La forma concreta que adopte este movimiento dependerá de la estructura global de la carta y de la posición del planeta regente, en este caso Júpiter. De cualquier manera, y en términos generales, podemos decir que éstas son vidas en expansión, [...] [CREA, 2001, Argentina]. 
Su función extraproposicional es evidente ya que no supera la prueba de la ecuandicionalidad (Gutiérrez Ordóñez 1997: 390): *Si de algún modo obtuvo el aplauso es en términos generales, ni otras propuestas para los marcadores (véase Greenbaum 1969; Fuentes Rodríguez 1996; Martín Zorraquino \& Portolés 1999):

46. Misa de Seis figuró en una de las últimas funciones de la temporada de Ópera Nacional — la más pobre y ridícula que ha podido conocer el público mexicano-, junto con Partita a pugni, lamentable engendro que no consigue desprestigiar espectáculos tan nobles como el box y la ópera y de cuya presentación sólo debemos recordar el trabajo de Jorge Delezé, un buen director que necesita mejores oportunidades. (O tal vez no: pondría en peligro el prestigio de muchos.) Si el Concierto para piano y percusiones obtuvo, en términos generales, el aplauso y la estimación de crítica y público, Misa de seis provocó desilusión, indiferencia y hasta el enojo de una señora que escribe sobre pintura [CREA, 1990, México].

Como puede apreciarse en los ejemplos, esta estructura actúa como una unidad, tiene una distribución sintáctica determinada, extraproposicional, aparece entre pausas con un contenido procedimental que apunta a lo enunciativo (generalización). Puede afirmarse que se comporta como un operador enunciativo de generalización. Convive con su distribución como circunstancial de modo de cualquier verbo y muy especialmente como complemento de un verbo de habla. Esta convivencia es común en el caso de los marcadores discursivos (véase Brinton 2010; Traugott 1995; Traugott \& Trousdale 2013; Aijmer et alii 2006; Aijmer \& Lewis 2017; Fischer 2006; Fraser 1996; Ranger 2018; Schiffrin 1987; Travis 2005; Fuentes Rodríguez 1996, 2018a [2009], etc.). Dicha multifuncionalidad no provoca ningún problema para la interpretación porque el contexto lo aclara:

Discourse particles are different from ordinary words in language because of the large number of pragmatic values that they can be associated with. Nevertheless speakers are not troubled by this multifunctionality (Aijmer 2002: 3).

\section{COLOCACIONES: HABLANDO, VISTO, DICHO EN TÉRMINOS GENERALES}

En términos generales, entre sus contextos de aparición más frecuentes, presenta la colocación con la forma hablando. Esta estructura forma un patrón discursivo, un complemento periférico de enunciación y marco. Esta construcción, hablando en términos generales, puede considerarse ya como un primer paso hacia lo macroestructural, pues 
aquí estamos ante un complemento periférico que actúa como grupo independiente y enmarca todo lo dicho. Aparece en posición inicial del enunciado, estableciendo un marco, o intercalada, estableciendo otro alcance:

47. Los routers Wi-Fi modernos también transmiten en frecuencias diferentes: 2,4 GHz y $5 \mathrm{GHz}$. Hablando en términos generales, $2,4 \mathrm{GHz}$ es mejor para las casas más grandes de varios niveles, ya que la señal viaja más lejos y puede penetrar las paredes con más facilidad. Pero para habitaciones o casas más pequeñas, $5 \mathrm{GHz}$ es la mejor opción: esta ofrece velocidades mucho más rápidas, aunque dentro de un rango de menor [...] [CORPES XXI, 2014, EE. UU.].

48. Hablando en términos generales, el quejigo es un árbol de tamaño medio, que raramente alcanza la veintena de metros de altura [CREA, 1998, España].

49. A esto hay que agregar que cuando los niños están en sus casas dedican una desproporcionada cantidad de horas a la televisión que, es hablando en términos generales, una escuela objetiva para la delincuencia o la inmoralidad [CREA, 1997, EE. UU.].

También la encontramos en posición final, como margen derecho del enunciado:

50. Porque podemos y debemos utilizar la regla de las mayorías para resolver todos los problemas que son competencia delas comunidades políticas, del Estado, hablando en términos generales [CREA, 2001, España $]^{5}$.

La más frecuente es la inicial ${ }^{6}$, ya sea de enunciado $(47,48)$, intervención $(51)$ u oración (52):

51. Ahora usted ha venido a Madrid a presentar una versión perfeccionada de aquel escáner, esta vez de funcionamiento vertical. ¿Qué le llevó a diseñar este artefacto?

Hablando en términos generales, los médicos siempre tienen que tratar con los síntomas de pacientes y determinar si su organismo funciona bien o no [CREA, 2003, España].

52. La tecnología progresa y, hablando en términos generales, puede decirse que la moral va en retroceso o ha entrado, por decir lo menos, en una grave crisis [CREA, 1997, EE. UU.].

También precede a una oración dependiente:

$5 \quad$ Nótese el cierto carácter reformulativo por su posición en el margen derecho.

6 En inicial de enunciado aparece menos. Así, en CREA los contextos de inicial de enunciado son de 19 frente a 35 (inicial de oración, intercalada o final) en una búsqueda de 1975-1979, y de 55 frente a 93, entre 2000 y 2004. 
53. Por supuesto, lo más grave lo ha determinado el hecho de que, hablando en términos generales, la escuela moderna de aberrante tendencia liberaloide ha estimulado en unos casos, y justificado en otros, los desmanes contra la moral de los niños, de los adolescentes y de los jóvenes [CREA, 1997, EE. UU.].

En términos generales forma parte también de otra colocación con función periférica (marco o circunstante). Así la encontramos con el participio visto/a:

54. En cuanto a la localización regional de la inversión, vista en términos generales, la Región Metropolitana sigue concentrando la mayor participación, con 18,5 por cierto [CREA, 1997, Chile].

Por último, la construcción absoluta con verbo de decir puede aparecer también con participio o infinitivo:

55. De esta forma, cualquiera que sea la frase que emite se constituye en predicado mío, o, dicho en términos generales, todo acto de habla es un predicado del hablante (como, por lo demás, lo es todo acto de conducta, pero ahora nos importan los actos de conducta verbales) [CREA, 1993, España].

56. No se trataba de una cuestión de intimidad, ni de que jesse fuera, por definirlo en términos generales, Miguel en la intimidad, de noche [CREA, 1991, España].

El grado de fijación de estas construcciones no es el mismo. Es más usado dicho en términos generales. Puede estar más cercano a una fijación, sobre todo porque utiliza una construcción ya empleada para la enunciación: «dicho entre paréntesis», «dicho en otras palabras»...

Estas colocaciones tienen diferente grado de fijación. Solo hablando en términos generales puede considerarse más avanzada en el proceso, pero aún se percibe como realización de un patrón discursivo que podríamos definir como Construcción Periférica Marco: [verbo decir + en términos generales]. El contenido es enunciativo de generalización como el del operador y afecta a dicho en términos generales, hablando en términos generales, por definirlo en términos generales.

\section{EN TÉRMINOS GENERALES, EN GENERAL, POR LO GENERAL, GENERALMENTE}

El adjetivo general aparece en otras combinatorias que se han fijado como operadores discursivos. Si buscamos en el diccionario académico, encontramos las siguientes definiciones: 


\section{En general, o por lo general}

1.locs. advs. En común, generalmente.

2.locs. advs. Sin especificar ni individualizar cosa alguna.

Puede acercarse a frecuentemente: 1. adv. De manera frecuente. En el Diccionario de conectores y operadores se define así:

\section{EN GENERAL.}

\section{Operador enunciativo}

1. Expresión limitativa que marca el ámbito de la aserción. Lo extiende a todos los casos, sin descender a los detalles, o sin entrar en casos particulares.

2. Se aplica a todo lo dicho en la oración, como marco asertivo, o a un segmento, en cuanto complemento de la predicación. Su posición varía: puede ir al inicio, intercalado o final, con o sin pausa: En general, las mujeres piensan más que los hombres y son más inteligentes (El Cultural, 17-10-2002)// [...]

3. Hay un caso en que aparece tras un sintagma nominal al que afecta, en contraposición con en particular. En este uso mantiene su valor léxico: Mejorar las condiciones de vida de la población en general y de las laderas en particular (Trama, 81, 3-2-2003)// [...] (Fuentes Rodríguez 2018a [2009]: 134).

\section{POR LO GENERAL.}

\section{Operador enunciativo}

1. Expresión limitativa que marca el ámbito de la aserción. Vid. en general: Si por lo general la poesía es, con contadísimas excepciones, un arte de minorías, en el caso de Imagen de Caín estamos ante una propuesta para la minoría de la minoría (El País, Babelia, 15-2-2003)// [...] (Fuentes Rodríguez 2018a [2009]: 279).

En el caso de generalmente, la RAE/ASALE nos señala que es "1. adv. De manera general. Rebatió una idea generalmente aceptada" (RAE/ASALE 2014, en línea). Su contenido apunta al campo de acción del elemento, en este caso de la aceptación. En este sentido conserva siempre ese valor de ámbito. Pero también presupone cierto estilo comunicativo en el que el hablante no precisa su pensamiento. En términos generales puede usarse con ese sentido extensivo (campo de aplicación) o enunciativo (aserción genérica, sin detalles). Encontramos algunos casos en que podría sustituirse por en general y por lo general, que expresan el primer valor, pero no afectan al decir:

57. Y es que, en términos generales, las diferencias entre ambos partidos son sobre todo de matices [CREA, 1983, Chile].

58. Del mismo modo, las culturas orientales se han caracterizado, en términos generales, por la ausencia de la técnica y de su conciencia correspondiente [CREA, 1982, España]. 
Sobre todo en este último podría fácilmente ser sustituible por en general. Su contenido afecta al ámbito de aplicación. Si lo tenemos con un valor claramente enunciativo, es más difícil sustituirlo. No podemos decir: «hablando por lo general», o «son los monoplazas más competitivos del 77 en general», en el ejemplo siguiente:

59. Evidentemente, los Lotus son los monoplazas más competitivos del 77, en términos generales, con tres victorias de Andretti y una y un segundo puesto de su compañero de equipo, Gunnar Nilsson [CREA, 1977, España].

\section{CONTENIDO PROCEDIMENTAL Y ESTRATEGIA DISCURSIVA}

Este contenido de generalización, que caracteriza la forma en términos generales, puede enmarcarse entre otras formas de expresión indirectas ${ }^{7}$. El hablante viola en cierto sentido la máxima de cantidad y calidad ya que no ofrece la información concreta; por tanto, puede entenderse que no aporta toda la que se le exige o no es de la calidad que sería deseable. De ahí nuestra clasificación como operador enunciativo: enmarca aquella información que quiere transmitir, en cierto modo advirtiendo al receptor de que no está siendo totalmente fiel a la verdad ni está proporcionando toda la cantidad de información que se requeriría para la comprensión plena de la entidad o hecho en cuestión. Su valor, por tanto, es limitador y por ello la encontramos en dos contextos: como marco, estableciendo desde el inicio las circunstancias interpretativas; o bien pospuesto, adquiriendo una función reinterpretativa, para adelantarse a posibles objeciones. Esa función reinterpretativa la suele expresar el margen derecho del enunciado (Fuentes Rodríguez 2012). El hablante realiza una aserción (definición, valoración, explicación, descripción, etc.), pero luego considera oportuno indicar que lo que ha enunciado hay que entenderlo de manera amplia, no detallada, obligando al receptor a volver sobre aquello que ya ha procesado, por lo que en realidad tenemos un nuevo acto enunciativo. Ahí reside la diferencia con la reformulación (Rossari 1990), donde tenemos el mismo contenido pero expresado de dos maneras diferentes, mientras que con la reinterpretación tenemos un nuevo acto enunciativo en el que lo dicho anteriormente ya no tiene el mismo valor de verdad ni de exhaustividad que se le había atribuido al inicio (vid. ejemplo 59).

Este comportamiento lo vemos tanto en el complemento de enunciación u operador, como en el complemento de ámbito, modificador verbal (60):

Véanse los complementos del acierto formulativo de Fant (2007). 
60. Se suele considerar la entrevista psiquiátrica en dos sentidos: con finalidad diagnóstica y con finalidad terapéutica. Esta división es válida en términos generales, pero debe saber que una entrevista diagnóstica, en la que se cumplan las reglas básicas sustentadas en el apartado dedicado a la relación psiquiatra-paciente, es ya una entrevista terapéutica [CREA, 1980, España].

Sucede sobre todo en el caso de la inmediatez comunicativa, donde el emisor no tiene tanta capacidad de planificación y tiende a realizar afirmaciones poco matizadas:

61. P. ¿Qué va a ocurrir en las próximas elecciones legislativas?

R. Yo lo que creo es que la gente no está muy motivada en términos generales. Puede haber un estado de indiferencia que a mí me parece muy negativo [CREA, 1989, España].

62. Recuérdese que, en términos generales, la doctrina niega la finalidad, identificando el «por qué» y el «para qué» [CREA, 1979, España].

La instrucción que ofrece el hablante es que está refiriéndose — hablando — a una determinada entidad de manera general para que el oyente no lo tome de manera literal o precisa. Por ejemplo, en este primer caso, se hace referencia a la represión en sentido genérico (incluye todo tipo de represiones) como una especie de hiperónimo y con una afirmación que no excluye otras:

63. Procesado: Perdone, señor, yo lo que quiero es cooperar, nada más. [sic]*En tres ensayos sobre la teoría de la sexualidad, Freud señala que la represión, en términos generales, proviene de la imposición de dominación de un individuo sobre otros, siendo ese primer individuo no otro que el padre [CREA, 1976, Argentina].

64. Además, cuando se empieza a tener como normal la eliminación de vidas humanas, entonces el crimen en términos generales tienda a considerarse normal [CREA, 1975, España].

La coaparición con términos como suele, tiende... refuerza esta estrategia de habla indirecta, poco precisa, para moverse en un plano más amplio.

Por último, podría pensarse que la necesidad de usar esta construcción como operador enunciativo por parte del hablante proviene de una estrategia para mostrar una menor implicación en lo dicho. Así se reducen los efectos negativos de la aserción $\left(\right.$ atenuación $^{8}$ ), evita los posibles ataques o réplicas por no precisar, y reduce también la valoración y la carga subjetiva de las aserciones:

En el caso de en términos generales consideramos que la atenuación (Briz y Albelda 2013, Fuentes Rodríguez 2010,2016) es un efecto contextual más que la naturaleza del elemento. Como hemos 
65. Aunque su capacidad no está en discusión, sí se teme que los instrumentos que use para lograr las metas del nuevo gobierno: en términos generales, reducir la inflación, descentralizar la economía, reformar el sistema tributario, acabar con la corrupción administrativa y — lo más inmediato - lograr un nuevo acuerdo con el Fondo Monetario Internacional (FMI) [CREA, 1985, Chile].

De hecho, encontramos ejemplos en los que el emisor/locutor reconoce que el hecho de referirse a una entidad o de enunciar algo de manera general no respeta del todo la máxima de calidad, de ahí que utilice nuestra construcción para enmarcar lo que dice y evitar esas posibles objeciones:

66. Y como quiera que, en términos generales, una persona bien entrenada suele tener buena salud (aunque esto no sea siempre cierto), actividad física y salud suelen utilizarse como causa y efecto [CREA, 1989, España].

Precisamente esta transgresión de la máxima de calidad (aunque también la de cantidad) es la que permite un efecto mitigador en muchas ocasiones, sobre todo en valoraciones positivas, algo que ya se daba cuando esta construcción funcionaba como complemento circunstancial:

67. Se advierten los nuevos métodos que Antonio Corencia ha adoptado, diferentes (también porque la obra así lo requería) de los habituales en las obras de corte clásico. Lo hace en términos generales acertadamente [CREA, 1980, España].

\section{RESULTADOS CUANTITATIVOS}

Para el estudio cualitativo de esta construcción, hemos tenido en cuenta todos los resultados del CREA. Para un análisis cuantitativo que pueda revelar cuál ha sido su periplo funcional hasta el español actual, hemos comparado los resultados de los primeros años del CREA (1975-1979) y los últimos (2001-2004) junto con los del CORPES XXI de este mismo periodo9. De este modo podremos tener una idea de la frecuencia de uso y de su posible proceso de fijación como operador. A continuación, presentamos una tabla en la que se muestran los resultados por funciones identificadas (tabla 1) y los porcentajes (tabla 2):

defendido en otros lugares (Fuentes Rodríguez 2018a), estas funciones pragmáticas pueden combinarse y aparecer en diversos grados de presencia.

9 Para una correcta interpretación de los resultados, hay que tener en cuenta que el $C R E A$ cuenta con 160 millones de formas en total, y el CORPES XXI, con 286 millones. 


\begin{tabular}{|l|c|c|c|c|c|}
\hline & $\begin{array}{c}\text { Número total de } \\
\text { casos }\end{array}$ & $\begin{array}{c}\text { Complemento } \\
\text { circunstancial }\end{array}$ & $\begin{array}{c}\text { Hablando } \\
\text { en términos } \\
\text { generales }\end{array}$ & $\begin{array}{c}\text { Complemento } \\
\text { marco de la } \\
\text { enunciación }\end{array}$ & $\begin{array}{c}\text { Complemento } \\
\text { enunciativo }\end{array}$ \\
\hline $\begin{array}{l}\text { CREA } \\
(1975-1979)\end{array}$ & 54 & 17 & 2 & 12 & 23 \\
\hline $\begin{array}{l}\text { CREA } \\
(2001-2004)\end{array}$ & 147 & 39 & 3 & 20 & 85 \\
\hline $\begin{array}{l}\text { CORPES XXI } \\
(2013-2016)\end{array}$ & 259 & 56 & 2 & 41 & 160 \\
\hline
\end{tabular}

TABLA 1. Número de casos en el corpus, por función

\begin{tabular}{|l|c|c|c|c|}
\hline & $\begin{array}{c}|c| \\
\text { Complemento } \\
\text { circunstancial }\end{array}$ & $\begin{array}{c}\text { Hablando en } \\
\text { términos generales }\end{array}$ & $\begin{array}{c}\text { Complemento } \\
\text { marco de la } \\
\text { enunciación }\end{array}$ & $\begin{array}{c}\text { Complemento } \\
\text { enunciativo }\end{array}$ \\
\hline CREA $(1975-1979)$ & $31 \%$ & $3 \%$ & $22 \%$ & $42 \%$ \\
\hline CREA $(2001-2004)$ & $26 \%$ & $2 \%$ & $13 \%$ & $57 \%$ \\
\hline $\begin{array}{l}\text { CORPES XXI } \\
(2013-2016)\end{array}$ & $21 \%$ & $0.7 \%$ & $15 \%$ & $51 \%$ \\
\hline
\end{tabular}

TABLA 2. Porcentajes en el corpus, según la función desempeñada

Como se comprueba, sí que existe un descenso de la función de complemento circunstancial y de complemento marco a la vez que aumenta, además en la misma proporción (ca. 10\%) la función de operador enunciativo. El incremento del número de casos puede tener que ver, o bien con la mayor disponibilidad de documentos en los corpus conforme se han ido configurando y consolidando como plataformas de recopilación de datos, o bien con el hecho de que el uso de este elemento se ha incrementado y se ha extendido fundamentalmente en su función de operador discursivo. No inclinaríamos por esta última explicación, ya que la nómina de ejemplos en el $C O R D E$ es de $240 \operatorname{casos}^{10}$. El primer caso se documenta en 1578, pero no es hasta 1729 cuando tenemos el primer uso como operador discursivo, en una obra del Padre Feijoo:

68. No falta quien, por patrocinar a Savonarola, atribuya a Comines la noticia de que aquel profetizó a Carlos VIII la muerte de el delfín y aun la de el rey mismo, como castigo de el cielo, si no volvía a Italia. Pero esto es mui falso. Lo que en Comines se halla es que Savonarola, en términos generales, amenazó al rey con el castigo divino, y Comines, viendo suceder poco después la muerte de el delfín, discurrió conjeturalmente que a este objeto se terminaba la amenaza de Savonarola [CORDE, España, 1729].

$10 \quad 171$ para la construcción en mayúscula inicial y 69 casos para la minúscula. 
Aquí estamos ya ante el uso como operador enunciativo, no hay ningún verbo de lengua del que dependa aunque esté aislado por pausas gráficas. No obstante, el segundo uso periférico que encontramos no vuelve a aparecer de nuevo hasta 1870$1901^{11}$, si bien se trata de un caso intermedio en el que funciona como marco de la enunciación: aparece el verbo de lengua, depende aún de él, pero ya el complemento aparece desligado entonativamente en el margen izquierdo:

69. Usos. -Bien puede considerarse que es también como el neurilema de los centros nerviosos y como su membrana nutricia, puesto que sirve para llevar á ellos los vasos; en términos generales, debe decirse que el número de venas que conduce es mucho mayor que el de las arterias, y también que abundan proporcionalmente más las venas en la pía-madre exterior y las arterias en la pía-madre interior [CORDE, España, 1870-1901].

Así, el siguiente uso como verdadero operador enunciativo no lo volvemos a encontrar hasta 1884 en una novela de Galdós:

70. La palabra del autor, narrando y describiendo, no tiene, en términos generales, tanta eficacia, ni da tan directamente la impresión de la verdad espiritual. Siempre es una referencia, algo como la Historia, que nos cuenta los acontecimientos y nos traza retratos y escenas. Con la virtud misteriosa del diálogo parece que vemos y oímos sin mediación extraña el suceso y sus actores, y nos olvidamos más fácilmente del artista oculto; pero no desaparece nunca, ni acaban de esconderle los bastidores del retablo, por bien construidos que estén [CORDE, España, 1884].

Como hemos comprobado, el hablante decide utilizar esta construcción para expresar el marco en el que inserta su enunciación, dada la rentabilidad de su base léxica.

\section{CONCLUSIONES}

En términos generales es una estructura multifuncional. Aparece en español como complemento del verbo (sobre todo con verbos de habla o nocionales), como complemento marco y como operador enunciativo de generalización. Presenta la información sin detenerse en detalles. La generalización es una operación enunciativa, contraria a

11 Hemos consultado la Biblioteca Virtual de Prensa Histórica del Ministerio de Cultura, por sugerencia de un evaluador, dado el salto en los datos del CORDE. Hemos encontrado documentado un caso de 1826: «Si de otro modo sucediese, sería legal cada presa que se hiciese después de notificado el bloqueo, pues que la prueba de este era la misma captura. Esta es en términos generales una de las normas fundamentales del derecho de bloqueo que profesa y ha practicado el Gobierno de Estados Unidos» (Diario Balear 17, 17-07-1826) y algún otro en 1950 y 1961. 
la especificación o concreción. Como contenido procedimental atenúa la fuerza de lo dicho y puede usarse para alejar o mitigar la implicación del hablante pero también los efectos discursivos en el oyente. El operador discursivo convive con las otras funciones y con colocaciones generalmente relativas a la enunciación. Asimismo, participa en correlaciones entre en particular - en general que sirve para establecer una relación cohesiva. Este contenido enunciativo desarrolla, como los aproximativos, una estrategia asertiva con grandes implicaciones argumentativas. Gestiona la relación con el receptor y ayuda a construir una imagen del hablante manteniéndose dentro de lo considerado apropiado.

\section{BIBLIOGRAFÍA}

AJjMer, K. (2002): English discourse particles: Evidence from a corpus, vol. 10. Amsterdam: John Benjamins Publishing.

AIJMER, K. et alii (2006): «Pragmatic markers in translation: a methodological proposal», Approaches to discourse particles 1, pp. 101-114.

Aijmer, K., \& D. Lewis (eds.) (2017): Contrastive analysis of discourse-pragmatic aspects of linguistic genres, vol. 5. Nueva York: Springer. https://doi. org/10.1007/978-3-319-54556-1

Austin, J. L. (1955): Cómo hacer cosas con palabras. Edición electrónica de www. philosophia.cl / Escuela de Filosofía Universidad ARCIS.

Benveniste, E. (1977): «El aparato formal de la enunciación», Problemas de lingüística general, vol. II. México: Siglo XXI, pp. 82-91.

Blanche-Benveniste, C. (2002): «Macro-syntaxe et micro-syntaxe: les dispositifs de la rection verbale», in H. Leth Andersen \& H. Nolke (eds.): Macro-syntaxe et mcro-sémantique: actes du colloque international d'Arhus, 17-19 mai 2001. Berna: Peter Lang, pp. 95-118.

BlANCHE-BENVENISTE, C. (2003): «Le recouvrement de la syntaxe et de la macro-syntaxe», in A. Scarano (ed.): Macro-syntaxe et pragmatique. L'analyse linguistique de l'oral. Roma: Bulzoni Editore, pp. 53-75. https://doi.org/10.3917/ss.003.0075

Brinton, L. J. (1996): Pragmatic Markers in English: Grammaticalization and Discourse Functions. Berlín: Mouton de Gruyter.

BRINTON, L. J. (2010): «Discourse Markers», in A. Jucker \& I. Taavitsainen (eds.): Historical Pragmatics. Berlin: Mouton de Gruyter, pp. 285-314.

Briz, A., S. Pons \& J. Portolés (2008-hoy): Diccionario de partículas discursivas. En línea. http://www.dpde.es/ (Última consulta, marzo de 2020). 
Briz Gómez, A. \& M. Albelda MARCo (2013): «Una propuesta teórica y metodológica para el análisis de la atenuación lingüística en español y portugués. La base de un proyecto en común (ES.POR.ATENUACIÓN)», Onomazéin 28, pp. 288-319. https://doi.org/10.7764/onomazein.28.21

Calsamiglia, H. \& A. Tusón (1999): Las cosas del decir. Manual de análisis del discurso. Barcelona: Ariel.

COMPANY, C. (2004a): «Gramaticalización por subjetivización como prescindibilidad de la sintaxis», Nueva Revista Filología Hispánica 52, 1, pp. 1-27. https://doi. org/10.24201/nrfh.v52i1.2226

Company, C. (2004b): «¿Gramaticalización o desgramaticalización? Reanálisis y subjetivización de verbos como marcadores discursivos en la historia del español», Revista de Filología Española 84, 1, pp. 29-66. https://doi.org/10.3989/rfe.2004. v84.i1.97

Dik, Simon C. (1997): The theory of Functional grammar, vol. 2. Berlin-New York: Mouton de Gruyter.

Ducrot, O. (1984): El decir y lo dicho. Buenos Aires: Hachette.

FANT, L. (2007): «La modalización del acierto formulativo en español», Revista Internacional de Lingüística Iberoamericana 5, 1 (9), pp. 39-58.

Fischer, K. (ed.) (2006): Approaches to Discourse Particles. Amsterdam: Elsevier.

Fraser, B. (1996): «Discourse markers», Pragmatics 6, 2, pp. 167-190. https://doi. org/10.1075/prag.6.2.03fra

FUENTES RodRíGUEZ, C. (1996): La sintaxis de los relacionantes supraoracionales. Madrid: Arco Libros.

Fuentes Rodríguez, C. (2005): «Hacia una sintaxis del enunciado», Lingüística Española Actual 27, 2, pp. 33- 61.

Fuentes RodríGuez, C. (2007): La sintaxis del enunciado: los complementos periféricos. Madrid: Arco Libros.

Fuentes RodrígueZ, C. (2010): La gramática de la cortesía en español/LE. Madrid: Arco Libros.

FuENTES RodríGuez, C. (2012): «El margen derecho del enunciado», Revista Española de Lingüística 42, 2, pp. 63-93.

Fuentes Rodríguez, C. (2014): «Comment Clauses and the Emergence of New Discourse Markers: Spanish lo que es más», Journal of Pragmatics 61, 1, pp. 103-119. https://doi.org/10.1016/j.pragma.2013.11.020 
Fuentes Rodríguez, C. (2015): «Operadores de comentario y argumentación», Spanish in context 12, 1, pp. 56-79. https://doi.org/10.1075/sic.12.1.04fue

Fuentes Rodríguez, C. (2016a): «Para colmo, scalar operator and additive connector. Keys to an evolving process», Journal of Historical Pragmatics 17, 1, pp. 79-106. https://doi.org/10.1075/jhp.17.1.04rod

Fuentes Rodríguez, C. (2016b): «Operadores discursivos: focalización, modalidad e intersubjetividad», in A. López Serena et alii (eds.): El español a través del tiempo. Estudios ofrecidos a Rafael Cano Aguilar. Sevilla: EUS, pp. 877-899.

Fuentes Rodríguez, C. (2016c): «Atenuación e intensificación estratégicas», in C. Fuentes Rodríguez (ed.): Estrategias argumentativas y discurso político. Madrid: Arco Libros, pp. 163-221.

Fuentes Rodríguez, C. (2017a [2000]): Lingüistica pragmática y análisis del discurso. Madrid: Arco Libros [3. a ed].

Fuentes Rodríguez, C. (2017b): «Macrosintaxis y lingüística pragmática», Círculo de Lingüística Aplicada a la Comunicación (CLAC) 71, pp. 5-34. https://doi. org/10.5209/CLAC.57301

Fuentes Rodríguez, C. (2018a [2009]): Diccionario de conectores y operadores del español. Madrid: Arco Libros [2 $2^{\mathrm{a}}$ ed.].

Fuentes Rodríguez, C. (2018b): «Teaching L2 Spanish discourse markers and pragmatic markers», in D. Dumitrescu \& P. L. Andueza (eds.): L2 Spanish Pragmatics: From Research to Practice. Abingdon: Taylor \& Francis/ Routledge, pp. 108-128. https://doi.org/10.4324/9781315276182-7

Fuentes Rodríguez, C. (2019): «Categorías discursivas y segmentación en macrosintaxis», in C. Fuentes Rodríguez \& S. Gutiérrez Ordóñez (eds.): Avances en macrosintaxis. Madrid: Arco Libros, pp. 15-66.

Gaulmyn (de) M. M. (1987): «Reformulation et planification métadiscursive», in J. Cosnier \& C. Kerbrat-Orecchioni (dirs.): Décrire la conversation. París: Presses Universitaries de Lyon.

GreENBAUM, S. (1969): Studies in English adverbial usage. London: Longman. GutiéRREZ OrdóÑEz, S. (1997): La oración y sus funciones. Madrid: Arco Libros. Hopper, P. J. (1991): «On some principles of Grammaticalization», in E. C. Traugott \& B. Heine (eds.): Approaches to Grammaticalization. Amsterdam: John Benjamins, pp. 17-35. https://doi.org/10.1075/tsl.19.1.04hop

Hopper, P. J. \& E. C. Traugott (2003): Grammaticalization. Cambridge: Cambridge University Press. https://doi.org/10.1017/CBO9781139165525 
Jucker, A. H. \& Y. ZIV (1998): Discursive markers: Descriptions and theory. Amsterdam: John Benjamins. https://doi.org/10.1075/pbns.57

LehmanN, C. (2002): «New Reflections on Grammaticalization ans Lexicalization», in I. Wischer \& G. M. Diewald (eds.): New Reflections on Grammaticalization. Amsterdam: John Benjamins, pp. 1-18. https://doi.org/10.1075/tsl.49.03leh

Martín Zorraquino, M. ${ }^{a}$ A. \& J. Portolés LÁzaro (1999): «Los marcadores del discurso», en I. Bosque \& V. Demonte (eds.): Gramática Descriptiva de la Lengua Española. Madrid: Espasa Calpe, pp. 4051-4213.

QUIRK, R. et alii (1972): A comprehensive gramar ofthe English Language. London: Longman.

Rossari, C. (1990): «Projet pour une typologie des opérations de reformulation», Cahiers de linguistique française 11, pp. 345-359.

RAE y ASALE (2014): Diccionario de la lengua española. Madrid: Espasa. En línea. https://dle.rae.es/ (Última consulta: marzo de 2020).

RAnger, G. (2018): Discourse Markers: An Enunciative Approach. Cham: Palgrave Macmillan. https://doi.org/10.1007/978-3-319-70905-5

RÉCANATI, F. (1979): La transparence et l'énonciation. Pour introduire à la pragmatique. Paris: Editions du Seuil.

Ross, J. R. (1970): «On Declarative Sentences», in R. A. Jacobs y P. S. Rosenbaum (eds.): Readings in English Transformational Grammar. Watham: Blaisdell Publishing Company, pp. 222-272.

Santos Río, L. (2003): Diccionario de partículas. Salamanca: Luso-española de ediciones.

Schiffrin, D. (1987): Discourse markers. Cambridge: Cambridge University Press. https://doi.org/10.1017/CBO9780511611841

TraugotT, E. C. (1995): The Role of the Development of Discourse Markers in a Theory of Grammaticalization. http://web.stanford.edu/ traugott/ectpapersonline.html [Última consulta: 05/05/2015].

Traugott, E. C. \& G. Trousdale (2013): Constructionalization and Constructional Changes. Oxford: Oxford University Press. https://doi.org/10.1093/ acprof:oso/9780199679898.001.0001

Travis, C. E. (2005): Discourse Markers in Colombian Spanish: A Study in Polysemy. Berlín: Mouton de Gruyter. 